\title{
Brotos de linhagens genéticas de soja: avaliação das propriedades físico-químicas
}

\author{
Sprouts of genetic soybean lines: evaluation of chemical-physical properties
}

\author{
Keli Cristina Cantelli ${ }^{1}$, Jéssica Tamiozzo Schmitd ${ }^{1}$, Marcelo Alvares de Oliveira ${ }^{2}$, Juliana Steffens ${ }^{1}$, \\ Clarice Steffens ${ }^{1}$, Rodrigo Santos Leite ${ }^{2}$, Mercedes Concórdia Carrão-Panizzi ${ }^{3 *}$ \\ ${ }^{1}$ Universidade Regional Integrada do Alto Uruguai e das Missões, Programa de Pós-graduação em Engenharia de Alimentos, Erechim/RS - Brasil \\ ${ }^{2}$ Empresa Brasileira de Pesquisa Agropecuária (Embrapa Soja), Londrina/PR - Brasil \\ ${ }^{3}$ Empresa Brasileira de Pesquisa Agropecuária (Embrapa Trigo), Passo Fundo/RS - Brasil
}

\section{${ }^{*}$ Corresponding Author:}

Mercedes Concórdia Carrão-Panizzi, Empresa Brasileira de Pesquisa Agropecuária (Embrapa Trigo), Rodovia BR-285, km 294, Caixa Postal: 3081, CEP: 99050-970, Passo Fundo/RS - Brasil, e-mail: mercedes.panizzi@embrapa.br

Cite as: Sprouts of genetic soybean lines: evaluation of chemical-physical properties. Braz. J. Food Technol., v. 20, e2016074, 2017.

Received: July 11, 2016; Accepted: Jan. 23, 2017

\section{Resumo}

Brotos de soja são vegetais de consumo direto, obtidos de grãos germinados, que são utilizados há séculos nos países orientais. Suas características nutritivas e a facilidade de produção têm chamado a atenção de consumidores do Ocidente. Sementes pequenas com alto poder germinativo e vigor são qualidades inerentes para produção de brotos. $\mathrm{Na}$ Embrapa, essas características têm sido contempladas no programa de melhoramento genético para obtenção de cultivares de soja especiais para o consumo humano. O objetivo deste trabalho foi produzir e caracterizar a qualidade de brotos de soja obtidos a partir das linhagens BRM09-10505, BRM10-60599 e PF133002, em comparação com a cultivar BRS 216, desenvolvida para ser utilizada como brotos ou natto. Os brotos foram produzidos em bandejas dispostas em câmara de germinação $\left(25^{\circ} \mathrm{C}\right.$ e $99 \%$ de umidade relativa). Sementes e brotos foram avaliados nos seguintes aspectos: teor de proteínas, lipídios, cinzas, isoflavonas, inibidor de tripsina Kunitz, ácido fítico, comprimento e peso dos brotos. As sementes da BRM09-10505 apresentaram 95\% de poder germinativo, seguida pela BRS 216 (93\%) e pelas outras linhagens (88\%, em média). A germinação pela mobilização dos compostos químicos aumentou os teores de proteínas $(8,96 \%)$ e de isoflavonas $(56,00 \%)$ e reduziu os teores de inibidor de tripsina Kunitz $(26,91 \%)$ e de ácido fítico $(13,78 \%)$. A cultivar BRS 216 apresentou o maior teor de proteína nas sementes $\left(41,96 \mathrm{~g} .100 \mathrm{~g} \mathrm{~g}^{-1}\right)$ e nos brotos $\left(47,70 \mathrm{~g} .100 \mathrm{~g} \mathrm{~g}^{-1}\right)$. A linhagem BRM09-10505 apresentou maior teor de inibidor de tripsina nas sementes (27,56 mg IT g$\left.{ }^{-1}\right)$ e nos brotos (19,62 $\left.\mathrm{mg}^{\text {IT g}}{ }^{-1}\right)$;

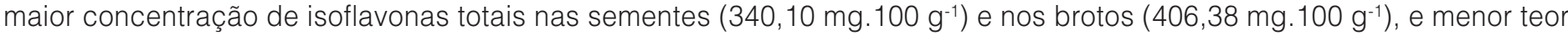
de ácido fítico nos brotos $\left(1,13 \mathrm{~g} .100 \mathrm{~g}^{-1}\right)$. Após quatro dias de germinação, destacaram-se, quanto ao comprimento e ao peso, a linhagem BRM09-10505 (8,03 cm e 214,36 g) e a cultivar BRS 216 (7,31 cm e 140,93 g). Entre as linhagens testadas, a linhagem BRM09-10505 apresentou bom potencial para produção de brotos.

Palavras-chave: Glycine max (L.) Merrill; Inibidor de tripsina Kunitz; Ácido fítico; Isoflavonas; Composição centesimal.

\section{Summary}

Soybean sprouts are vegetables for direct consumption obtained from germinated grains, which have been used for centuries in Eastern countries. Their nutritional characteristics and ease of production have attracted the attention of consumers from Western countries. Small seeds with high germinating power and vigour are inherent qualities for shoot production. At the Brazilian Agricultural Research Corporation - Embrapa, these characteristics have been considered in the genetic breeding program to obtain special soybean cultivars for human consumption. The aim of this study was to produce and characterize the quality of soybean sprouts from the genetic lines BRM09-10505, BRM10-60599 and PF133002, in comparison with the cultivar BRS 216, which was developed for use as sprouts and natto. Trays placed in a growth chamber $\left(25^{\circ} \mathrm{C}\right.$ and $99 \%$ relative humidity) were used for produce the sprouts. The protein, lipid, ash, isoflavones, Kunitz trypsin inhibitor and phytic acid contents were analysed in the seeds and sprouts. The length and weight of the sprouts were also determined. Seeds of the line BRM09-10505 showed 95\% germinating power followed by BRS 216 (93\%) and the other lines (88\% on average). 
Germination, by mobilizing chemical compounds, increased the protein (8.96\%) and isoflavone (56.00\%) contents, and reduced the concentrations of the Kunitz trypsin inhibitor (26.91\%) and phytic acid (13.78\%). The cultivar BRS 216 presented the highest protein content in the seeds (41.96 g.100 g-1) and sprouts (47.70 g.100 g-1). The line BRM09-10505 had the highest trypsin inhibitor content in the seeds (27.56 $\mathrm{mg} \mathrm{IT} \mathrm{g}^{-1}$ ) and in the sprouts (19.62 $\mathrm{mg} \mathrm{IT} \mathrm{g}^{-1}$ ); the highest

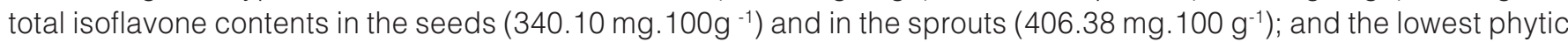
acid content in the sprouts $\left(1.13 \mathrm{~g} .100 \mathrm{~g}^{-1}\right)$. After four days of germination, the length and weight of the sprouts were, respectively, $8.03 \mathrm{~cm}$ and $214.36 \mathrm{~g}$ for line BRM09-10505 and $7.31 \mathrm{~cm}$ and $140.93 \mathrm{~g}$ for BRS 216. Of the lines tested, BRM09-10505 showed good potential for sprout production.

Keywords: Glycine max (L.) Merrill; Kunitz trypsin inhibitor; Phytic acid; Isoflavones; Centesimal composition.

\section{Introdução}

O Brasil é o segundo maior produtor de soja do mundo, com produção de crescimento constante. Na safra 2013/14, foram colhidas $86.120,8$ milhões de toneladas de grãos da commodity e, na safra (2014/15), a produção foi de 96.222,1 milhões de toneladas, representando um incremento de $11,7 \%$ em relação ao montante produzido no ano de 2014 (CONAB, 2015). Embora o grande mercado de soja seja para a commodity, nichos de mercado para soja alimento, para utilizações de consumo direto, como hortaliças, são possibilidades a ser consideradas para produtores e processadores (CARRÃO-PANIZZI et al., 2016).

A soja pode dar origem a diferentes produtos e coprodutos da indústria química, de alimentos e de energia (biocombustíveis) (SILVA et al., 2006). O consumo de soja como alimento pela população tem aumentado devido aos benefícios para a saúde, pois é fonte proteica de alta qualidade, além de fornecer compostos bioativos, como as isoflavonas, entre outros (CARRÃO-PANIZZI; SILVA, 2011). A importância da soja como alimento e sua influência na manutenção da saúde humana têm referências históricas na Ásia, principalmente China e Japão, pois, há milênios, foi nomeada como um dos cinco grãos sagrados pelo Imperador Chinês Sheng-Nung (MESSINA et al., 1994). Nos países ocidentais, ainda há necessidade de adaptar a soja ao gosto do consumidor não acostumado com a soja como alimento. Pelo melhoramento genético da soja, é possível a obtenção de cultivares especiais que sejam mais apropriadas a diferentes utilizações (CARRÃO-PANIZZI et al., 2012).

Dependendo das características do grão da soja, o mesmo pode ser utilizado para diferentes finalidades. A soja tipo grão, que apresenta sementes de tamanhos médios (peso de cem sementes (PCS) de $15 \mathrm{~g}$ ) é utilizada principalmente para atender às indústrias de farelo $e$ óleo. A soja tipo alimento apresenta sabor mais suave e agradável ao paladar humano e pode apresentar sementes grandes, com PCS igual ou maior do que $20 \mathrm{~g}$, e sementes pequenas com PCS igual a $10 \mathrm{~g}$, destinadas para produção de soja brotos e natto (YOKOMIZO et al., 2000). A cultivar de soja BRS 216 é a primeira e única cultivar brasileira que possui características apropriadas para a produção de brotos, em função do tamanho reduzido de sementes (PCS igual a 10,4 g) e do elevado conteúdo proteico (43,6\%) (CARRÃO-PANIZZI et al., 2003).

Os brotos de soja são uma opção nutritiva e saudável de consumo, porque são produzidos sem agroquímicos e apresentam alto teor de minerais, vitaminas e proteínas, além de baixo teor calórico (VIEIRA; LOPES, 2001).

Segundo Vieira e Lopes (2001), a produção de brotos apresenta uma série de vantagens, porque o processo de germinação é rápido, pois, em até seis dias, os brotos apresentam tamanho adequado para o consumo; ocupa espaço reduzido; não necessita de luz solar direta; pode ser realizada a qualquer época do ano; não há a necessidade de solos, fertilizantes ou agrotóxicos; não requer região específica para produção, e apresenta rendimento compensatório. A qualidade dos brotos é dependente da qualidade das sementes, que devem apresentar alta pureza física, poder germinativo e vigor.

Fatores antinutricionais presentes na soja diminuem suas qualidades nutritivas. Os inibidores de proteases, principalmente o inibidor de tripsina Kunitz, provocam inibição do crescimento, hipertrofia e hiperplasia pancreática em animais (MIURA et al., 2005). No entanto, seus efeitos fisiológicos positivos para a saúde humana também têm sido relatados (KENNEDY, 1994, 1995; KENNEDY; WAN, 2002). Nos alimentos à base de soja, esses inibidores podem estar em concentração residual não superior a 20\% (LIENER, 1994).

O ácido fítico constitui cerca de 1 a $5 \%$ do peso de muitos cereais e leguminosas, e diminui a biodisponibilidade de minerais por causa de sua interação com cátions multivalentes, formando complexos insolúveis (CHERYAN; RACKIS, 1980). Por outro lado, o ácido fítico, pelo seu efeito quelante com íons minerais, pode bloquear a oxidação de lipídios, agindo como antioxidante (SHAMSUDDIN, 2002).

Isoflavonas são compostos bioativos presentes na soja, chamados de fitoestrógenos com potenciais propriedades quimiopreventivas (LAMPE, 2003), os quais são constituídos por cerca de 70 a $80 \%$ de malonil- $\beta$-glicosídeos, $5 \%$ de acetil- $\beta$-glicosídeos, $25 \%$ de $\beta$-glicosídeos e menos de $2 \%$ de agliconas (LEE; LEE, 2009). As formas agliconas são mais biodisponíveis e se encontram em maior quantidade 
nos alimentos fermentados ou naqueles alimentos cujos processamentos facilitem a hidrólise dos glicosídeos (GÓES-FAVONI et al., 2010; SETCHELL et al., 2001).

O processo de germinação melhora o valor nutritivo do grão por causa das mudanças na bioquímica do mesmo, as quais dependem do tipo de planta, da genética e das condições de germinação (MARTINEZ et al., 2011). Portanto, desde que os brotos sejam consumidos diretamente, do ponto de vista nutricional, é interessante que apresentem alto teor proteico, reduzido teor de fatores antinutricionais e maior teor de isoflavonas agliconas.

A produção de brotos de soja no Brasil ainda é restrita, principalmente devido à falta de cultivares de soja com características apropriadas. O potencial de mercado para brotos de soja é importante, no que se refere à oportunidade de agregação de valor à soja como produção para pequenos empreendedores, produtores e processadores. A tecnologia para produção de brotos lançada pela Embrapa Soja (OLIVEIRA; CARRÃO-PANIZZI, 2016) mostra a viabilidade desse nicho de mercado especial de soja. Portanto, o objetivo deste trabalho foi avaliar os brotos de três linhagens de soja, que apresentam sementes pequenas, quanto às suas características físico-químicas, ao teor de isoflavonas e à atividade de inibidor de tripsina e ácido fítico.

\section{Material e métodos}

Foram utilizadas sementes de soja da cultivar BRS 216 e das linhagens BRM09-10505, BRM10-60599 e PF133002, do programa de melhoramento genético da Embrapa da safra 2014/2015. As sementes foram cedidas pela Embrapa Trigo, Passo Fundo-RS.

Para a experimentação, amostras de $100 \mathrm{~g}$ de sementes de soja, previamente selecionadas para retirada de grãos chochos e doentes, foram sanitizadas em solução de hipoclorito de sódio a 10\%, de acordo com metodologia descrita por Oliveira et al. (2013), por 4 min. Posteriormente, as sementes foram enxaguadas em água corrente e colocadas em embebição em água potável (OLIVEIRA et al., 2013). Em seguida, $100 \mathrm{~g}$ de sementes foram colocados em recipientes plásticos com furos no fundo, sendo tampados para garantir ausência da luz.

O processo de germinação ocorreu em câmara com temperatura controlada (marca Menoncin ${ }^{\circledR}$ ) a $25^{\circ} \mathrm{C}$, $99 \%$ de umidade, e frequência de irrigação a cada $12 \mathrm{~h}$, por quatro dias.

Para definir o tempo de germinação, testes preliminares foram realizados com a cultivar BRS 216 . O tempo de germinação foi definido em quatro dias, porque, nesse período de tempo, os brotos apresentavam $7 \mathrm{~cm}$ de comprimento. Oliveira et al. (2013) observaram que, com cinco dias de germinação, os brotos da BRS 216 atingiram o comprimento médio de $8,06 \mathrm{~cm}$. No quarto dia de germinação, procedeu-se à colheita dos brotos, considerando aqueles que atingiram comprimento acima de $5 \mathrm{~cm}$.

Para produção de brotos de soja, as sementes da cultivar BRS 216 e das linhagens foram analisadas em relação à qualidade física e ao tamanho das sementes (peso de cem sementes (PCS). Três amostras de cem sementes separadas aleatoriamente foram pesadas em balança de precisão (0,001 g) (BRASIL, 1992).

Para a avaliação do poder germinativo das sementes, utilizou-se a metodologia descrita por Brasil (1992), sendo utilizadas, para cada amostra de soja, quatro repetições de 50 sementes. As sementes foram semeadas em papel toalha umedecido com água destilada, em quantidade equivalente a três vezes a massa do papel seco. Conforme a metodologia do rolo em papel, as sementes foram depositadas entre as folhas de papel umedecidas, as quais foram embrulhadas na forma de rolos, identificadas e colocadas em câmara com temperatura controlada, $\pm 25^{\circ} \mathrm{C}$ e $99 \%$ de umidade. Após quatro dias da semeadura, realizou-se a contagem das plântulas normais. Os resultados foram expressos em porcentagem de plântulas normais.

A composição química das sementes e dos brotos de soja foi determinada por meio de análises de umidade, proteínas, lipídios e cinzas, utilizando os métodos descritos pela AOAC (2007).

A análise quantitativa das diferentes formas de isoflavonas nas sementes e nos brotos foi realizada segundo metodologia preconizada por Berhow (2002). A extração das diferentes formas de isoflavonas foi realizada conforme Carrão-Panizzi et al. (2002). A separação e a quantificação das isoflavonas foram realizadas em coluna de fase reversa do tipo ODS C18 (YMC-Pack ODS-AM, S-5 $\mu \mathrm{m}, 120$ A, com diâmetro de 4,6 mm e $250 \mathrm{~mm}$ de comprimento), utilizando-se cromatógrafo líquido (HPLC - WATERS, 2690).

Para quantificação do inibidor de tripsina nas sementes e nos brotos, utilizou-se a metodologia desenvolvida por Kakade et al. (1974). O método se baseia no grau de inibição da tripsina e na hidrólise de substrato benzoil-DL-argininap-nitroanilida hidrocloreto (BAPA). Os resultados foram expressos como miligramas de inibidor de tripsina (IT) por grama de amostra desengordurada.

O ácido fítico (AF) nas sementes e nos brotos foi determinado por cromatografia de troca iônica, segundo metodologia descrita por Latta e Eskin (1980), com modificações de Ellis e Morris (1986). Para a determinação do teor de ácido fítico, pesou-se $1 \mathrm{~g}$ de amostra previamente moída em Erlenmeyer de $125 \mathrm{~mL}$ e adicionaram-se $10 \mathrm{~mL}$ de solução $\mathrm{HCl}$ 0,8M. Colocou-se em agitação em agitador magnético (Velp Scientifica ${ }^{\circledR}$ ) durante $2 \mathrm{~h}$. Depois dessa etapa, centrifugou-se (centrífuga MPW ${ }^{\circledast}$, modelo 351R) a $2.000 \mathrm{rpm}$ durante $10 \mathrm{~min}$, para a obtenção do sobrenadante contendo ácido fítico. Pipetaram-se $2 \mathrm{~mL}$ 
Brotos de linhagens genéticas de soja: avaliação das propriedades físico-químicas

Cantelli, K. C. et al.

desse sobrenadante e foram transferidos para balão de $50 \mathrm{~mL}$, completando-se esse volume com água milli-Q. Em seguida, foi realizada a separação, pela técnica de cromatografia de troca iônica, e a quantificação, pela técnica de espectrofotometria de UV/visível (Spectro Vision ${ }^{\circledR}$ modelo DB-1880S) a $500 \mathrm{~nm}$. Os resultados foram expressos em $\mathrm{g} .100 \mathrm{~g}^{-1}$.

Nos brotos colhidos no quarto dia de germinação, foram avaliados o comprimento $(\mathrm{cm})$ e o peso $(\mathrm{g})$, em triplicata. Foram considerados brotos viáveis somente aqueles que obtiveram comprimento acima de $5 \mathrm{~cm}$. O comprimento foi medido em centímetros, com paquímetro (Starrett ${ }^{\circledR}$ modelo Universal Série 125). O peso dos brotos viáveis foi determinado em balança semianalítica e expresso em gramas.

Os resultados foram submetidos à análise de variância (ANOVA) e as médias, comparadas pelo Teste de Tukey em nível de 95\% de confiança, utilizando o Software Statistica 8.0.

\section{Resultados e discussão}

O teste de germinação é utilizado com o objetivo de avaliar a qualidade fisiológica das sementes e permite conhecer o potencial de germinação de um lote em condições favoráveis (CARVALHO; NAKAGAWA, 2000). No teste, a linhagem BRM09-10505 apresentou maior porcentagem de germinação (94\%), seguida pela cultivar BRS 216 (93\%) e pelas linhagens PF 133002 (89\%) e BRM10-60599 (87\%). Dependendo da cultivar e das condições de produção e de armazenamento, o poder germinativo das sementes pode variar. Quando o objetivo é produção de brotos, o poder germinativo das sementes é determinante para a qualidade e o rendimento.

O peso de cem sementes das linhagens BRM10-60599 e PF 133002 mostrou-se semelhante (12,13g e 11,86g, respectivamente). A cultivar BRS 216 e a linhagem BRM09-10505 apresentaram sementes menores, com pesos de 10,51g e 10,42g, respectivamente. Levando em consideração que, para produção de brotos, são desejáveis sementes menores, a BRS 216 e a linhagem BRM09-10505 apresentam-se, portanto, mais indicadas para essa finalidade. Além do tamanho menor, as sementes devem ser de alta pureza física, sem contaminação de outras espécies, ter alto vigor e poder germinativo (VIEIRA; LOPES; 2001).
Após quatro dias de germinação, observou-se que a BRM09-10505 apresentou maior peso de brotos, seguida da cultivar BRS 216 (Tabela 1), o que pode ser consequência do seu melhor poder germinativo (94\%).

O peso de brotos viáveis (rendimento), observado neste trabalho, após quatro dias de germinação, foi de 140,93 g, valor semelhante, quando avaliado, proporcionalmente, ao valor observado por Oliveira et al. (2013), que utilizaram a cultivar BRS 216 e obtiveram, a partir de $25 \mathrm{~g}$ de sementes germinadas por cinco dias, 35,73 g de brotos de soja.

O comprimento dos brotos, após quatro dias de germinação, mostrou que não houve diferenças significativas $(p<0,05)$ entre a BRS 216 e a linhagem BRM09-10505 (comprimento médio de 7,67 cm), e entre os genótipos BRM10-60599 e PF 133002 (comprimento médio de $5,64 \mathrm{~cm}$ ) (Tabela 1). Na Figura 1, é apresentada uma imagem do tamanho dos brotos das diferentes cultivares.

Oliveira et al. (2013) verificaram que o comprimento dos brotos da cultivar BRS 216 aumentou em função dos dias de germinação, sendo que os valores médios de comprimento foram $7,74 \mathrm{~cm}, 11,11 \mathrm{~cm}$ e $13,77 \mathrm{~cm}$ para brotos germinados por 5, 6 e 7 dias, respectivamente, e com irrigação a cada 12 h. Vilas Boas et al. (2002), estudando o comprimento de brotos de soja, observaram valores variando de 4,30 cm (três dias de germinação) a

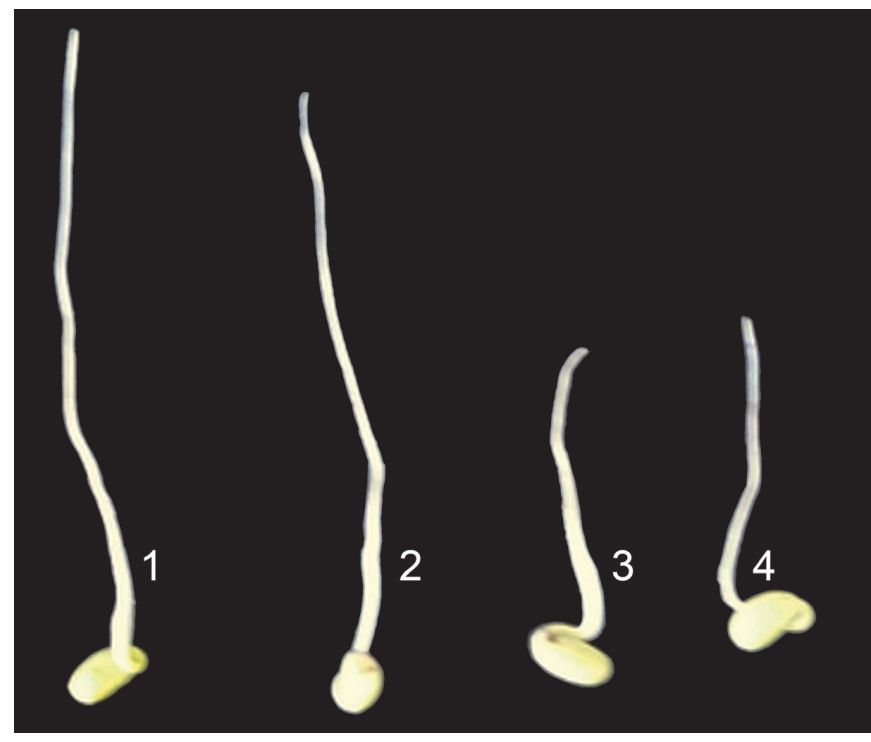

Figura 1. Tamanho dos brotos de soja após quatro dias de germinação; (1) BRM09-10505, (2) BRS 216, (3) BRM10-60599 e (4) PF 133002.

Tabela 1. Peso e comprimento de brotos da cultivar de soja BRS 216 e das linhagens de soja.

\begin{tabular}{lcrrr}
\multicolumn{1}{c}{ Parâmetros físicos } & BRS 216 & \multicolumn{4}{c}{ Linhagens } \\
\cline { 2 - 5 } & & BRM09-10505 & BRM10-60599 & PF133002 \\
Peso (g) & $140,93( \pm 1,23)^{\mathrm{b}}$ & $214,36( \pm 1,75)^{\mathrm{a}}$ & $60,70( \pm 2,27)^{\mathrm{d}}$ & $67,62( \pm 1,15)^{\mathrm{c}}$ \\
Comprimento $(\mathbf{c m})$ & $7,31( \pm 0,95)^{\mathrm{a}}$ & $8,03( \pm 1,05)^{\mathrm{a}}$ & $5,30( \pm 0,45)^{\mathrm{b}}$ & $5,98( \pm 0,36)^{\mathrm{b}}$ \\
\hline
\end{tabular}

Médias ( \pm desvio padrão) seguidas de letras iguais nas linhas não diferem no nível de $5 \%$ (Teste de Tukey). 
$9,80 \mathrm{~cm}$ (seis dias de germinação). Em comparação com o presente estudo, pode-se observar que a cultivar BRS 216 e a BRM09-10505, em quatro dias de germinação, apresentaram brotos com comprimento médio superior. Quinhone Júnior e Ida (2015) observaram que os brotos da cultivar BRS 284 aumentaram quatro vezes em comprimento, de $48 \mathrm{~h}$ a $120 \mathrm{~h}$, sendo que houve uma estabilização no crescimento até 168 horas, o que pode ser devido à menor disponibilidade de nutrientes nesse período. Para melhor aparência visual dos brotos, estes não podem ser nem muito compridos, nem muito curtos, sendo que comprimentos de 8 a $10 \mathrm{~cm}$ podem ser um bom critério. Medidas de crescimento e peso dos brotos determinam o rendimento dos mesmos, e são influenciadas pela frequência de irrigação e pelo tempo de desenvolvimento (OLIVEIRA et al., 2013). Outros fatores, tais como cultivares, condições de colheita e de armazenamento, que interferem na qualidade das sementes, também afetam rendimento dos brotos (SILVA et al., 2010). Quinhone Júnior e Ida (2015) observaram que o efeito do tempo de germinação aumentou 2,5 vezes o peso fresco de cem brotos, entre 48 e 168 h de germinação.

O teor de proteínas aumentou significativamente $(p<0,05)$ nos brotos de todos os genótipos estudados, pois, durante a germinação, ocorreu a síntese enzimática proteica, mudando a composição dos constituintes químicos (BAU et al., 1997; BARCELOS et al., 2002). A cultivar BRS 216 apresentou o maior teor de proteínas, tanto para as sementes como para os brotos (Tabela 2), e esses resultados confirmaram as observações de Carrão-Panizzi et al. (2009b), que também verificaram o alto teor proteico dessa cultivar. Oliveira et al. (2013) também observaram elevado teor de proteínas (47,90 g.100 g-1) nos brotos da cultivar BRS 216 que foram germinados por cinco dias. A linhagem PF 133002 apresentou menor teor de proteínas e maior teor de lipídeos, conforme correlação negativa entre esses compostos (BURTON 1984).

Segundo a Tabela Brasileira de Composição de Alimentos - TACO (UNICAMP, 2011), a soja possui em torno de $36 \%$ de teor proteico, o feijão preto $(21,3 \%)$, a ervilha em vagem $(7,5 \%)$ e o amendoim $(27,2 \%)$, sendo que a soja se destaca em relação às outras leguminosas quanto ao conteúdo de proteína. Além de ser vegetal fonte de proteínas, brotos de soja também fornecem vitamina $C$ e pró-vitamina A, as quais, em grãos maduros de soja, se apresentam em baixos teores (BATES; MATTHEWS, 1975).

A composição química da soja depende de vários fatores, o que inclui diferenças genéticas das cultivares, anos de cultivo, localização geográfica e estresses ambientais (PIPER; BOOTE, 1999). Benassi et al. (2011), avaliando o teor de lipídeos nas sementes das cultivares BRS 257 e BRS 267, constataram um teor lipídico de 20,19 e 18,55 g. $100 \mathrm{~g}^{-1}$, respectivamente. Entre as linhagens, foram observadas diferenças significativas para os teores de proteínas e lipídeos nas sementes (Tabela 2).

Com a germinação, o teor de lipídeos aumentou nos brotos da cultivar BRS 216 e das linhagens BRM09-10505 e BRM10-60599 (Tabela 2). Donangelo et al. (1995), estudando o efeito de germinação, por $48 \mathrm{~h}$, verificaram aumento no teor dos lipídeos de $21,1 \%$ nas sementes para $22,4 \%$ nos brotos de soja e de $1,4 \%$ nas sementes para 1,8\% nos brotos de feijão (Phaseolus vulgaris L.). Entretanto, Oliveira et al. (2013) observaram que o teor de lipídeos nas sementes também pode diminuir com a evolução do tempo de germinação, pois, com cinco dias de germinação, o teor de lipídeos nos brotos foi mais elevado, e se reduziu com mais dias de crescimento e menor a frequência de irrigação. Tal fato se justifica pela mobilização das reservas nutricionais das sementes durante o processo germinativo. Como verificado pelos outros autores, Vilas Boas et al. (2002) também observaram uma redução de 18 para $10 \mathrm{~g} .100 \mathrm{~g}^{-1}$ de massa seca no teor de lipídeos dos brotos de soja, com o aumento no tempo de crescimento de três para seis dias.

Em relação ao teor de cinzas, não foi verificada diferença significativa $(p>0,05)$ nas sementes analisadas. Rigo et al. (2015) também não observaram diferenças nas cultivares de soja BRS 267, Vmax e BRS 257, as quais apresentaram um teor médio de 4,89 g.100 g-1. Resultados similares foram obtidos por Martinez et al. (2011), que obtiveram valores para cinzas de $5,11 \mathrm{~g} .100 \mathrm{~g}^{-1}$ para sementes de soja antes da germinação. Nos brotos, houve aumento no teor de cinzas em comparação com as sementes

Tabela 2. Teor de proteínas, lipídeos e cinzas nas sementes e brotos da cultivar BRS 216 e das linhagens de soja.

\begin{tabular}{|c|c|c|c|c|c|}
\hline \multirow{2}{*}{ Análises $\left(\mathrm{g} .100 \mathrm{~g}^{-1}\right)$} & & \multirow{2}{*}{ BRS 216} & \multicolumn{3}{|c|}{ Linhagens } \\
\hline & & & BRM09-10505 & BRM10-60599 & PF 133002 \\
\hline \multirow{2}{*}{ Proteínas } & Sementes & $41,96( \pm 0,25)^{a B}$ & $38,72( \pm 0,05)^{\mathrm{bB}}$ & $37,63( \pm 0,57)^{\mathrm{CB}}$ & $36,27( \pm 0,28)^{d B}$ \\
\hline & Brotos & $47,70( \pm 0,05)^{\mathrm{aA}}$ & $40,29( \pm 0,50)^{b c A}$ & $40,80( \pm 0,19)^{\mathrm{bA}}$ & $39,79( \pm 0,21)^{C A}$ \\
\hline \multirow{2}{*}{ Lipídeos } & Sementes & $19,45( \pm 0,32)^{\mathrm{dB}}$ & $20,66( \pm 0,27)^{\mathrm{cB}}$ & $21,98( \pm 0,08)^{\mathrm{bB}}$ & $22,61( \pm 0,18)^{\mathrm{aA}}$ \\
\hline & Brotos & $24,75( \pm 0,12)^{\mathrm{aA}}$ & $23,38( \pm 0,14)^{\mathrm{bA}}$ & $23,47( \pm 0,40)^{\mathrm{bA}}$ & $22,78( \pm 0,14)^{\mathrm{CA}}$ \\
\hline \multirow{2}{*}{ Cinzas } & Sementes & $4,91( \pm 0,30)^{a A}$ & $4,89( \pm 0,16)^{\mathrm{aB}}$ & $4,96( \pm 0,04)^{\mathrm{aB}}$ & $4,71( \pm 0,17)^{\mathrm{aB}}$ \\
\hline & Brotos & $5,35( \pm 0,04)^{\mathrm{CA}}$ & $5,67( \pm 0,19)^{\mathrm{bcA}}$ & $6,16( \pm 0,20)^{\mathrm{abA}}$ & $6,36( \pm 0,29)^{\mathrm{aA}}$ \\
\hline
\end{tabular}

Média (três repeticões) \pm desvio padrão seguida de letras iguais minúsculas nas linhas e maiúsculas nas colunas, para cada grupo de análises, indica não haver diferença significativa em nível de 5\% (Teste de Tukey). 
(Tabela 2), sendo que as linhagens BRM10-60599 e PF 133002 apresentaram maior teor, com valor médio de 6,26 (g.100 $\mathrm{g}^{-1}$ ), semelhante ao obtido por Oliveira et al. (2013), em que, após cinco dias de germinação, a BRS 216, com irrigação a cada $12 \mathrm{~h}$, apresentou valor de 6,53 g. Esse aumento no teor de cinzas pode ser devido a uma maior massa nos brotos em relação às sementes, o que está de acordo com o descrito por Bau et al. (1997), os quais relataram que, em brotos, a concentração de minerais aumenta cerca de 15\%.

Para melhorar a qualidade nutricional da soja e utilizá-la como alimento, há necessidade de inativar o inibidor de tripsina para menos de 20\% da atividade inibitória encontrada na soja crua (LIENER, 1994). A germinação pela mobilização de compostos nas sementes pode ser uma boa alternativa para a melhora do valor nutritivo, que também depende das características genéticas da soja e das diferentes condições de germinação (SANGRONIS; MACHADO, 2007).

Rigo et al. (2015), analisando sementes de soja da cultivar BRS 267, observaram um teor de inibidor de tripsina Kunitz (ITK) de 16,57 mg IT g-1 . Entre os genótipos analisados neste trabalho, observaram-se diferenças significativas $(p<0,05)$ para o teor de ITK nas sementes (Tabela 3). Fatores genéticos e ambientais podem afetar as concentrações de ITK (SILVA et al., 2010). O processo de germinação e obtenção dos brotos pode ser considerado como uma alternativa para a redução de fatores antinutricionais. Neste trabalho, se observou que, quando as sementes de todos os genótipos foram germinadas, houve, em média, uma redução significativa de $26,91 \%$ no teor de ITK (Tabela 3).

Observou-se que, nos brotos em relação às sementes, os teores de ITK foram reduzidos a $27,6 \%$ na BRS 216; 28,8\% na BRM09-10505; 20,7\% na BRM10-60599, e $30,5 \%$ na PF 133002, valores estes obtidos pela relação ITKsementes / ITKbrotos (Tabela 3). Em estudo realizado por Oliveira et al. (2013), em diferentes tempos de germinação e com frequência de irrigação a cada $4 \mathrm{~h}$, os valores ITK também se reduziram com a germinação, obtendo 13,06, 11,82 e 7,21 mg IT g ${ }^{-1}$, para 5, 6 e 7 dias de germinação, respectivamente.
Quanto ao teor de ácido fítico nas sementes, o maior valor encontrado foi para a BRM10-60599 (1,60 g.100 g-1) e o menor, para a BRM09-10505 (1,30 g.100 g-1) (Tabela 3). Segundo Moreira et al. (2012), vários fatores podem influenciar para que haja diferença no teor de ácido fítico nas sementes de soja, tais como: variabilidade genética, local de cultivo e fatores climáticos. Os autores analisaram o teor de ácido fítico nas sementes de soja da cultivar BRS 217 cultivadas em Londrina-PR e Candido Mota-SP, e verificaram diferenças no teor de 1,13 g.100 $\mathrm{g}^{-1} \mathrm{e}$ 2,43 g.100 $\mathrm{g}^{-1}$, respectivamente.

Para os brotos, o teor de ácido fítico foi menor em relação às sementes, diferindo $(p<0,05)$ estatisticamente entre os genótipos (Tabela 3). O ácido fítico é um dos fatores responsáveis pela redução da biodisponibilidade de minerais (MOREIRA et al., 2012), mas também pode atuar como antioxidante potente em sistemas alimentares (SHAMSUDDIN, 2002). Com a germinação, houve uma redução, em média, de 22,6\% do teor de ácido fítico (Tabela 3). Martinez et al. (2011) analisaram a cultivar de soja M. SOY RR, antes e após germinação por 48 h, e verificaram que apesar de ter havido redução no teor de ácido fítico, não houve diferença estatística entre as amostras, sendo que os valores foram de 1,36 g.100 $\mathrm{g}^{-1}$ antes da germinação e de 1,27 g.100 g ${ }^{-1}$ após a germinação por $48 \mathrm{~h}$.

O teor de isoflavonas totais nas sementes apresentou diferença $(p>0,05)$ significativa entre os genótipos estudados (Tabela 4). O teor de isoflavonas nas sementes de soja pode diferir de acordo com a cultivar, a época de plantio, as condições climáticas e do solo, o local de cultivo e a incidência de estresses bióticos no local de plantio (BERGER et al., 2008). Carrão-Panizzi et al. (2009a) analisaram o teor de isoflavonas em 233 cultivares de soja semeadas em Ponta Grossa-PR, na safra de 2001/2002, e verificaram uma variação de $12 \mathrm{mg} .100 \mathrm{~g}^{-1}$ a $461 \mathrm{mg} .100 \mathrm{~g}^{-1}$ entre as cultivares. Variabilidade no teor de isoflavonas nas sementes também foi observada entre os genótipos analisados neste trabalho (Tabela 4). Todas as formas de isoflavonas tiveram seu teor aumentado nos brotos, com diferenças $(p>0,05)$ significativas entre genótipos (Tabela 4). As formas glicosiladas apresentaram, nas sementes, conteúdos de 34,70 mg. $100 \mathrm{~g}^{-1}$ e, para os brotos, de $51,43 \mathrm{mg} .100 \mathrm{~g}^{-1}$, em que se pode verificar

Tabela 3. Teor do inibidor de tripsina Kunitz e de ácido fítico nas sementes e nos brotos da cultivar BRS 216 e nas linhagens de soja

\begin{tabular}{cccccc}
\multicolumn{1}{c}{ Análises } & BRS 216 & \multicolumn{4}{c}{ Linhagens } \\
\cline { 4 - 6 } & & BRM09-10505 & BRM10-60599 & PF 133002 \\
\multirow{2}{*}{ ITK (mg IT.g $\left.{ }^{-1}\right)$} & Sementes & $21,68( \pm 0,52)^{\mathrm{bA}}$ & $27,56( \pm 0,28)^{\mathrm{aA}}$ & $18,35( \pm 0,34)^{\mathrm{dA}}$ & $20,29( \pm 0,32)^{\mathrm{cA}}$ \\
& Brotos & $15,68( \pm 0,35)^{\mathrm{bB}}$ & $19,62( \pm 0,16)^{\mathrm{aB}}$ & $14,55( \pm 0,08)^{\mathrm{cB}}$ & $14,10( \pm 0,08)^{\mathrm{cB}}$ \\
\multirow{2}{*}{ Ácido fítico $\left(\mathrm{g} .100 \mathrm{~g}^{-1}\right)$} & Sementes & $1,53( \pm 0,06)^{\mathrm{abA}}$ & $1,30( \pm 0,03)^{\mathrm{CA}}$ & $1,60( \pm 0,04)^{\mathrm{aA}}$ & $1,44( \pm 0,01)^{\mathrm{bA}}$ \\
& Brotos & $1,17( \pm 0,06)^{\mathrm{CB}}$ & $1,13( \pm 0,04)^{\mathrm{CB}}$ & $1,47( \pm 0,01)^{\mathrm{aB}}$ & $1,29( \pm 0,01)^{\mathrm{bB}}$ \\
\hline
\end{tabular}

Média (três repetições) \pm desvio padrão seguida de letras iguais minúsculas nas linhas e maiúsculas nas colunas, para cada grupo de análises, indica não haver diferença significativa em nível de 5\% (Teste de Tukey). 
Brotos de linhagens genéticas de soja: avaliação das propriedades físico-químicas

Cantelli, K. C. et al.

Tabela 4. Teor de isoflavonas (mg. $100 \mathrm{~g}^{-1}$ ) nas sementes e nos brotos da cultivar BRS 216 e nas linhagens de soja.

\begin{tabular}{|c|c|c|c|c|c|}
\hline \multirow{2}{*}{ Isoflavonas (mg.100 g-1) } & & \multirow{2}{*}{ BRS 216} & \multicolumn{3}{|c|}{ Linhagens } \\
\hline & & & BRM09-10505 & BRM10-60599 & PF 133002 \\
\hline \multirow{2}{*}{ Glicosiladas } & Sementes & $19,72( \pm 0,24)^{\mathrm{CB}}$ & $66,39( \pm 0,58)^{a \mathrm{~B}}$ & $20,67( \pm 1,70)^{\mathrm{CB}}$ & $32,03( \pm 1,27)^{\mathrm{bB}}$ \\
\hline & Brotos & $41,84( \pm 1,49)^{\mathrm{CA}}$ & $77,56( \pm 2,51)^{\mathrm{aA}}$ & $35,11( \pm 0,95)^{d A}$ & $51,24( \pm 2,99)^{b A}$ \\
\hline \multirow{2}{*}{ Malonil-Glicosiladas } & Sementes & $119,57( \pm 2,48)^{\mathrm{bB}}$ & $253,98( \pm 1,78)^{\mathrm{aB}}$ & $89,25( \pm 3,57)^{\mathrm{CB}}$ & $91,87( \pm 5,44)^{\mathrm{CB}}$ \\
\hline & Brotos & $148,63( \pm 0,70)^{\mathrm{bA}}$ & $289,03( \pm 0,33)^{\mathrm{aA}}$ & $96,75( \pm 0,79)^{\mathrm{dA}}$ & $121,42( \pm 1,12)^{\mathrm{cA}}$ \\
\hline \multirow{2}{*}{ Agliconas } & Sementes & $14,00( \pm 2,38)^{\mathrm{bB}}$ & $19,73( \pm 1,83)^{\mathrm{aB}}$ & $9,19( \pm 1,54)^{\mathrm{CB}}$ & $8,15( \pm 3,28)^{\mathrm{CB}}$ \\
\hline & Brotos & $34,89( \pm 1,04)^{\mathrm{bA}}$ & $39,79( \pm 1,28)^{\mathrm{aA}}$ & $21,21( \pm 1,63)^{\mathrm{CA}}$ & $16,54( \pm 1,85)^{\mathrm{dA}}$ \\
\hline \multirow{2}{*}{ Isoflavonas Totais } & Sementes & $153,29( \pm 0,33)^{\mathrm{bB}}$ & $340,10( \pm 3,03)^{a B}$ & $119,11( \pm 6,82)^{\mathrm{dB}}$ & $132,05( \pm 5,62)^{\mathrm{cB}}$ \\
\hline & Brotos & $225,36( \pm 3,24)^{\mathrm{bA}}$ & $406,38( \pm 4,94)^{\mathrm{aA}}$ & $153,07( \pm 0,85)^{\mathrm{dA}}$ & $189,20( \pm 7,07)^{\mathrm{cA}}$ \\
\hline
\end{tabular}

Média (três repetições) \pm desvio padrão seguida de letras iguais minúsculas nas linhas e maiúsculas nas colunas, para cada grupo de análises, indica não haver diferença significativa em nível de 5\% (Teste de Tukey).

que houve um aumento de 48,21\% após a germinação (Tabela 4). Kim et al. (2005) observaram um aumento médio de 179 vezes na concentração de $\beta$-glicosídeos em sete cultivares de soja, germinadas por cinco dias a $25^{\circ} \mathrm{C}$ e com presença de luz, condição pela qual os autores justificaram esse aumento tão elevado. As formas malonil-glicosiladas, em média, foram predominantes nas sementes $(74,21 \%)$ e nos brotos $(67,33 \%)$ para os quatro genótipos analisados, em relação ao total de isoflavonas (Tabela 4). Tsukamoto et al. (1995), analisando sementes de sete cultivares de soja, observaram resultados similares, sendo que o percentual de malonil-glicosídeos variou entre $67,00 \%$ e 93,00\%, em relação ao total de isoflavonas. Quinhone Júnior e Ida (2014) avaliaram o efeito do tempo de germinação sobre o teor das diferentes formas de isoflavonas nos cotilédones, na radícula e no hipocótilo, e verificaram que o processo de germinação por 168 horas aumentou a concentração de isoflavonas nos cotilédones, enquanto que agliconas foram detectadas somente no hipocótilo e na radícula.

Neste trabalho, cujas observações não consideraram partes dos brotos, observou-se que a forma aglicona teve sua concentração aumentada nos brotos em decorrência do processo germinativo das sementes (Tabela 4).

Com quatro dias de germinação, o teor de agliconas aumentou 49,21\% para a cultivar BRS 216; 49,58\% para a linhagem BRM09-10505; 43,32\% para a linhagem BRM10-60599, e 49,27\% para a linhagem PF 133002. Huang et al. (2014) observaram um teor inicial de

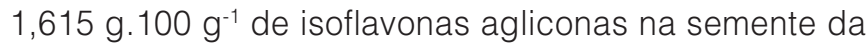
soja e, após três dias de germinação, esse teor atingiu 3,99 g. $100 \mathrm{~g}^{-1}$.

As agliconas são as formas de isoflavonas mais biodisponíveis (FERREIRA et al., 2011). Segundo Carrão-Panizzi et al. (2003), para maior formação de agliconas na matéria prima para processamentos de alimentos funcionais à base de soja, é importante considerar a escolha de cultivares que geneticamente apresentam teor elevado de isoflavonas, bem como de tecnologias de processamento, cujas temperaturas e períodos de tempo permitam o desenvolvimento desses compostos na soja. Chiarello et al. (2006) investigaram a influência da germinação sobre o perfil de isoflavonas e observaram uma redução de 1,1 vez no teor total de isoflavonas e um aumento de 7,0 vezes no teor de agliconas após sete dias de germinação, a $22^{\circ} \mathrm{C}$ e ausência de luz. O teor de isoflavonas totais dos brotos foi maior na linhagem BRM09-10505, seguida pela cultivar BRS 216 (Tabela 4), sendo que esses dois genótipos apresentaram um aumento médio de 28,04\% no teor de isoflavonas totais após o processo de germinação. Galão et al. (2009) verificaram diferenças no teor de isoflavonas totais nas sementes de soja, entre cultivares e locais de semeadura. Para sementes de soja cultivadas em Londrina-PR e Ponta Grossa-PR, a cultivar BRS 267 apresentou uma variação de 271,82 a 319,14 mg. $100 \mathrm{~g}^{-1}$ e a cultivar BRS 257, de 431,33 a 319,14 mg. $100 \mathrm{~g}^{-1}$, respectivamente. Portanto, o teor de isoflavonas nas sementes pode variar, dependendo das diferenças genéticas das cultivares e dos ambientes de cultivo, sendo que esse teor ainda será alterado com a germinação, que proporciona aumento desses compostos nos brotos de soja. A linhagem BRM09-10505 apresentou maior teor de isoflavonas em todas as formas analisadas (Tabela 4), sendo que tanto seus grãos como os brotos apresentam-se como uma boa opção para o consumo humano.

A produção de brotos de soja pela germinação das sementes é um processo de baixo custo, que utiliza pouca mão de obra e equipamentos, e se constitui numa alternativa para a agroindústria familiar. Portanto, o broto de soja é um produto nutritivo saudável que, com maior valor agregado, pode viabilizar pequenos empreendimentos.

Neste trabalho, além do estudo sobre as modificações na composição química da soja germinada para produção de brotos, a avaliação de linhagens de soja com sementes pequenas mostrou-se importante, porque fornece informações sobre materiais com potencial de recomendação para cultivo comercial. No Brasil, o desenvolvimento de germoplasma competitivo e apropriado para produção de 
Brotos de linhagens genéticas de soja: avaliação das propriedades físico-químicas

Cantelli, K. C. et al.

brotos é necessário, já que somente a cultivar BRS 216 é indicada para esse produto. Os resultados mostraram que a linhagem BRM09-10505 foi efetiva na produção de brotos, pois apresenta boa composição química, sementes pequenas e rendimento. Fatores agronômicos, como, principalmente, adaptação e rendimento de grãos, devem também ser considerados por ocasião da recomendação comercial da linhagem.

\section{Conclusões}

Modificações bioquímicas no processo de germinação aumentaram o teor de proteínas e de isoflavonas, e reduziram o teor do inibidor de tripsina e ácido fítico. A cultivar BRS 216 apresentou maior teor de proteínas nas sementes e nos brotos. A linhagem BRM09-10505 apresentou maior atividade do inibidor de tripsina e de isoflavonas totais, e menor teor de ácido fítico, além de um desenvolvimento adequado dos brotos quanto ao rendimento e ao tamanho (maior peso de brotos viáveis). Desta forma, a linhagem BRM09-10505, que apresenta sementes pequenas (10 g por peso de cem sementes), pode se apresentar como uma alternativa potencial para recomendação de matéria prima a ser utilizada na produção de brotos de soja.

\section{Referências}

ASSOCIATION OF OFFICIAL ANALYTICAL CHEMISTS - AOAC. Official methods of analysis of the Association of Official Analytical Chemists. 18th ed. Washington: AOAC, 2007. $3000 \mathrm{p}$.

BARCELOS, M. F. P.; VILAS BOAS, E. V. B.; LIMA, M. A. C. Aspectos nutricionais de brotos de soja e de milho combinados. Ciência e Agrotecnologia, Lavras, v. 26, n. 4, p. 817-825, 2002.

BATES, R. P.; MATTHEWS, R. F. Ascorbic acid and beta carotene in soybeans as influenced by maturity, sprouting, processing and storage. Proceedings of the Florida State Horticultural Society, Tallahassee, v. 88, p. 4-6, 1975.

BAU, H. M.; VILLAUME, C.; NICOLAS, J. P.; MEJEAN, L. Effect of germination on chemical composition, biochemical constituents and antinutritional factors of soya bean (Glycine max) seeds. Journal of the Science of Food and Agriculture, London, v. 73, p. 1-9, 1997

BENASSI, V. T.; BENASSI, M. T.; PRUDENCIO, S. H. Cultivares brasileiras de soja: características para a produção de tofu e aceitação pelo mercado consumidor. Semina: Ciências Agrárias, Londrina, v. 32, n. 1, p. 1901-1914, 2011. http://dx.doi. org/10.5433/1679-0359.2011v32Suplp1901.

BERGER, M.; RASOLOHERY, C. A.; CAZALIS, R.; DAYDÉ, J. Isoflavone accumulation kinetics in soybean seed cotyledons and hypocotyls: distinct pathways and genetic controls. Crop Science, Madison, v. 48, n. 2, p. 700-708, 2008. http://dx.doi. org/10.2135/cropsci2007.08.0431.
BERHOW, M. A. Modern analytical techniques for flavonoid determination. In: BUSLIG, B. S.; MANTHEY, J. A. (Ed.). Flavonoids in the living cell. New York: Klusher Academic, 2002. p. 61-76.

BRASIL. Ministério da Agricultura e Reforma Agrária. Regras para análise de sementes. Brasília: SNDA/DNDV/CLAV, 1992.

BURTON, J. W. Breeding soybeans for improved protein quantity and quality. In: SHIBLES, R. (Ed.). WORLD SOYBEAN RESEARCH CONFERENCE, 3., 1984, Ames. Proceedings... Boulder: Westview Press, 1984. p. 361-367

CARRÃO-PANIZZI, M. C.; BERHOW, M.; MANDARINO, J. M. G.; OLIVEIRA, M. C. N. Environmental and genetic variation of isoflavone content of soybean seeds grown in Brazil. Pesquisa Agropecuária Brasileira, Brasília, v. 44, n. 11, p. 1444-1451, 2009a. http://dx.doi.org/10.1590/S0100-204X2009001100011.

CARRÃO PANIZZI, M. C.; PÍPOLO, A. E.; MANDARINO, J. M. G.; ARANTES, N. E.; GARCIA, A.; BENASSI, V. T.; ARIAS, C. A.; KASTER, M.; OLIVEIRA, M. F.; OLIVEIRA, M. A.; TOLEDO, J. F. F.; MOREIRA, J. U. V.; CARNEIRO, G. E. S. Breeding specialty soybean cultivars for processing and value-added utilization at Embrapa in Brazil. In: WORLD SOYBEAN RESEARCH CONFERENCE - WSRC, 8., 2009, Beijing. Proceedings... Beijing: Chinese Academy of Agricultural Sciences/Institute of Crop Science, 2009b. CD-ROM.

CARRÃO-PANIZZI, M. C.; BERTAGNOLLI, P. F.; MOREIRA, J. U. V.; DA COSTA, L. C.; CARAFFA, M.; COSTAMILAN, L. M.; STRIEDER, M. L. Melhoramento de soja para alimentação humana na Embrapa Trigo - safra agrícola 2015/2016. In: COSTAMILAN, L. M.; CARRÃO-PANIZZI, M. C. (Ed.). Soja: resultados de pesquisa 2015/2016. Passo Fundo: Embrapa Trigo, 2016. p. 25-30. (Documentos 161). Disponível em: <http://ainfo.cnptia.embrapa. br/digital/bitstream/item/147718/1/ID43759-2016D0161p25.pdf>. Acesso em: 04 de mar. 2016.

CARRÃO-PANIZZI, M. C.; BERTAGNOLLI, P. F.; STRIEDER, M. L.; COSTAMILAN, L. M.; MOREIRA, J. U. V. Melhoramento de soja para alimentação humana na Embrapa Trigo - Safra agrícola 2011/2012. Passo Fundo: Embrapa Trigo, 2012. p. 27-31.

CARRÃO-PANIZZI, M. C.; FAVONI, S. P. G.; KIKUCHI, A. Extraction time for soybean isoflavone determination. Brazilian Archives of Biology and Technology: an International Journal, Londrina, v. 45, n. 4, p. 515-518, 2002. http://dx.doi.org/10.1590/S151689132002000600015.

CARRÃO-PANIZZI, M. C.; SILVA, J. B. Soja na alimentação humana: qualidade na produção de grãos com valor agregado. In: CONGRESO DE LA SOJA DEL MERCOSUR - MERCOSOJA, 5., 2011, Rosário. Resumos... Rosário: Asociación de la Cadena de la Soja Argentina, 2011. p. 1-3.

CARRÃO-PANIZZI, M. C.; SIMÃO, A. S.; KIKUCHI, A. Efeitos de genótipos, ambientes e de tratamentos hidrotérmicos na concentração de isoflavonas agliconas em grãos de soja. Pesquisa Agropecuária Brasileira, Brasília, v. 38, n. 8, p. 897-902, 2003. http://dx.doi.org/10.1590/S0100-204X2003000800001. 
Brotos de linhagens genéticas de soja: avaliação das propriedades físico-químicas

Cantelli, K. C. et al.

CARVALHO, N. M.; NAKAGAWA, J. Sementes: ciência, tecnologia e produção. 4. ed. Jaboticabal: Funep, 2000. 588 p.

CHERYAN, M.; RACKIS, J. J. Phytic acid interactions in food systems. CRC Critical Reviews in Food Science and Nutrition, Cleveland, v. 13, n. 4, p. 297-335, 1980. PMid:7002470. http:// dx.doi.org/10.1080/10408398009527293.

CHIARELLO, M. D.; GUERROUE, J.-L. L.; CHAGAS, C. M. S.; FRANCO, O. L.; BIANCHINI, E.; JOAO, M. J. Influence of heat treatment and grain germination on the isoflavone profile of soy milk. Journal of Food Biochemistry, Westport, v. 30, n. 2, p. 234-247, 2006. http://dx.doi.org/10.1111/j.1745-4514.2006.00058.x.

COMPANHIA NACIONAL DE ABASTECIMENTO - CONAB. Acompanhamento da safra brasileira de grãos. Brasília: julho 2015. p. 1-109. (v. 2, Safra 2014/15. n. 10, Décimo levantamento). Disponível em: <http://www.conab.gov.br>. Acesso em: 13 de set. 2015

DONANGELO, C. M.; TRUGO, L. C.; TRUGO, N. M. F.; EQQUM, B. O. Effect of germination of legume seeds on chemical composition and on protein and energy utilization in rats. Food Chemistry, Britain, v. 53, n. 1, p. 23-27, 1995. http://dx.doi. org/10.1016/0308-8146(95)95781-Z.

ELLIS, R.; MORRIS, R. Appropriate resin selection for rapid phytate analysis by ion-exchange chromatography. Cereal Chemistry, Saint Paul, v. 63, p. 58-59, 1986.

FERREIRA, M. P.; OLIVEIRA, M. C. N.; MANDARINO, J. M. G.; SILVA, J. B.; IDA, E. I.; CARRÃO-PANIZZI, M. C. Changes in the isoflavone profile and in the chemical composition of tempeh during processing and refrigeration. Pesquisa Agropecuária Brasileira, Brasília, v. 46, n. 11, p. 1555-1561, 2011. http:// dx.doi.org/10.1590/S0100-204X2011001100018.

GALÃO, O. F.; CARRÃO-PANIZZI, M. C.; MANDARINO, J. M. G.; LEITE, R. L. Teor de isoflavonas em vinte cultivares de soja semeadas em Londrina e Ponta Grossa. In: JORNADA ACADÊMICA DA EMBRAPA SOJA, 5., 2009, Londrina. Resumos... Londrina: Embrapa Soja, 2009. p. 127-129. (Documentos 323).

GÓES-FAVONI, S. P.; CARRÃO-PANIZZI, M. C.; BELEIA, A. Changes in isoflavone in soybean cotyledons soaked in different volumes of water. Food Chemistry, London, v. 119, n. 4, p. 16051612, 2010. http://dx.doi.org/10.1016/j.foodchem.2009.09.051.

HUANG, X.; CAI, W.; XU, B. Kinetic changes of nutrients and antioxidant capacities of germinated soybean (Glycine max L.) and mung bean (Vigna radiata L.) with germination time. Food Chemistry, Zhuhai, v. 143, p. 268-276, 2014. PMid:24054239. http://dx.doi.org/10.1016/j.foodchem.2013.07.080.

KAKADE, M. L.; RACKIS, J. J.; MCGHEE, J. E.; PUSKI, G. Determination of trypsin inhibitor activity of soy products: a collaborative analysis of improved procedure. Cereal Chemistry, Saint Paul, v. 51, p. 376-383, 1974.

KENNEDY, A. R. Prevention of carcinogenesis by protease inhibitors. Cancer Research, Baltimore, v. 54, n. 7, p. 1999S2005S, 1994. Suplemento. PMID: 8137328
KENNEDY, A. R. The evidence for soybean products as cancer preventive agents. The Journal of Nutrition, Rockville, v. 125, n. 3, p. 733S-743S, 1995. Suplemento. PMid:7884559.

KENNEDY, A. R.; WAN, X. S. Effects of the Bowman-Birk inhibitor on growth, invasion, and clonogenic survival of human prostate epithelial cells and prostate cancer cells. The Prostate, New York, v. 50, n. 2, p. 125-133, 2002. PMid:11816021. http://dx. doi. org/10.1002/pros. 10041

KIM, W. J.; LEE, H. Y.; WON, M. H.; YOO, S. H. Germination effect of soybean on its contents of isoflavones and oligosaccharides. Food Science and Biotechnology, Seoul, v. 14, n. 4, p. 498-502, 2005.

LAMPE, J. W. Isoflavonoid and lignan phytoestrogens as dietary biomarkers. The Journal of Nutrition, Rockville, v. 133, p. 956S964S, 2003. Suplemento 3. PMid:12612182.

LATTA, M.; ESKIN, M. A simple and rapid method for phytate determination. Journal of Agricultural and Food Chemistry, Washington, v. 28, n. 6, p. 313-315, 1980. http://dx.doi.org/10.1021/ jf60232a049.

LEE, S. W.; LEE, J. H. Effects of oven-drying, roasting, and explosive puffing process on isoflavone distributions in soybeans. Food Chemistry, London, v. 112, n. 2, p. 316-320, 2009. http:// dx.doi.org/10.1016/j.foodchem.2008.05.065.

LIENER, I. E. Implications of antinutritional components in soybean foods. Critical Reviews in Food Science and Nutrition, Boca Raton, v. 34, n. 1, p. 31-67, 1994. PMid:8142044. http://dx.doi. org/10.1080/10408399409527649.

MARTINEZ, A. P. C.; MARTINEZ, P. C. C.; SOUZA, M. C.; BRAZACA, S. G. C. Alterações químicas em grãos de soja durante a germinação. Ciência e Tecnologia de Alimentos, Campinas, v. 31, n. 1, p. 23-30, 2011

MESSINA, M.; MESSINA, V.; SETCHELL, K. The simple soybean and your health. New York: Avery Publishing Group, 1994. p. 35-36

MIURA, E. M. Y.; SILVA, R. S. S. F.; MIZUBUTI, I. Y.; IDA, E. I. Cinética de inativação de inibidores de tripsina e de insolubilização de proteínas de diferentes cultivares de soja. Revista Brasileira de Zootectecnia, Viçosa, v. 34, n. 5, p. 1659-1665, 2005.

MOREIRA, A. A.; MANDARINO, J. M. G.; NEVES-SOUZA, R. D.; LEITE, R. S.; OLIVEIRA, M. A. Teor de ácido fítico em cultivares de soja cultivados em diferentes regiões dos estados do Paraná e São Paulo. Alimentos e Nutrição, Araraquara, v. 23, n. 3, p. 393-398, 2012.

OLIVEIRA, M. A.; CARRÃO-PANIZZI, M. C. Tecnologia para produção de brotos de soja. Londrina: Embrapa Soja, 2016. p. 7. Comunicado Técnico, 90.

OLIVEIRA, M. A.; CARRÃO-PANIZZI, M. C.; MANDARINO, J. M. G.; LEITE, R. S. Produção de brotos de soja utilizando a cultivar BRS 216: Caracterização físico-química e teste de aceitabilidade. 
Brotos de linhagens genéticas de soja: avaliação das propriedades físico-químicas

Cantelli, K. C. et al.

Journal of Food Technology, Campinas, v. 16, n. 1, p. 34-41, 2013. http://dx.doi.org/10.1590/S1981-67232013005000009.

PIPER, E. L.; BOOTE, K. I. Temperature and cultivar effects on soybean seed oil and protein concentrations. Journal of the American Oil Chemists' Society, Champaign, v. 76, n. 10, p. 1233-1240, 1999. http://dx.doi.org/10.1007/s11746-999-0099-y.

QUINHONE JÚNIOR, A.; IDA, E. I. Isoflavones of the soybean components and the effect of germination time in the cotyledons and embryonic axis. Journal of Agricultural and Food Chemistry, Washington, v. 62, p. 8452-8459, 2014. PMID: 25070365. http:// dx.doi.org/10.1021/jf502927m.

QUINHONE JÚNIOR, A.; IDA, E. I. Profile of the contents of different forms of soybean isoflavones and the effect of germination time on these compounds and the physical parameters in soybean sprouts. Food Chemistry, London, v. 166, p. 173-178, 2015. PMid:25053043. http://dx.doi.org/10.1016/j.foodchem.2014.06.012.

RIGO, A. A.; DAHMER, A. M.; STEFFENS, C.; STEFFENS, J. Characterization of soybean cultivars genetically improved for human consumption. International Journal of Food Engineering, Berkeley, v. 1, n. 1, 2015. http://dx.doi.org/10.18178/ijfe.1.1.1-7.

SANGRONIS, E.; MACHADO, C. J. Influence of germination on the nutritional quality of Phaseolus vulgaris and Cajanus cajan. Food Science and Technology, Campinas, v. 40, p. 116-120, 2007. http://dx.doi.org/10.1016/j.Iwt.2005.08.003.

SETCHELL, K. D. R.; BROWN, N. M.; DESAI, P.; ZIMMERNECHEMIAS, L.; WOLFE, B. E.; BRASHEAR, W. T.; KIRSCHNER, A. S.; CASSIDY, A.; HEUBI, J. E. Bioavailability of pure isoflavones in healthy humans and analysis of commercial soy isoflavone supplements. The Journal of Nutrition, Rockville, v. 131, n. 4, p. 1362S-1375S, 2001. Suplemento. PMid:11285356.

SHAMSUDDIN, A. M. Anti-cancer function of phytic acid. International Journal of Food Science \& Technology, Oxford, v. 37, n. 7, p. 769-782, 2002. http://dx.doi.org/10.1046/j.13652621.2002.00620.x.
SILVA, C. O.; ANDRADE, G. F.; DANTAS, M. I. S.; COSTA, N. M. B.; PELUZIO, M. C. G.; FONTES, E. A. F.; MARTINO, H. S. D. Influência do processamento na qualidade proteica de novos cultivares de soja destinados à alimentação humana. Revista de Nutrição, Campinas, v. 23, n. 3, p. 389-397, 2010. http:// dx.doi.org/10.1590/S1415-52732010000300007.

SILVA, M. S.; NAVES, M. M. V.; OLIVEIRA, R. B.; LEITE, O. S. M. Composição química e valor proteico de resíduo de soja em relação ao grão de soja. Ciência e Tecnologia de Alimentos, Campinas, v. 26, n. 3, p. 571-576, 2006. http://dx.doi.org/10.1590/ S0101-20612006000300014.

TSUKAMOTO, C.; SHIMADA, S.; IGITA, K.; KUDOU, S.; KOKUBUN, M.; OKUBO, K.; KITAMURA, K. Factors affecting isoflavone content in soybean seeds: changes in isoflavones, saponins, and composition of fatty acids at different temperatures during seed development. Journal of Agricultural and Food Chemistry, Washington, v. 43, n. 5, p. 1184-1192, 1995. http:// dx.doi.org/10.1021/jf00053a012.

UNIVERSIDADE ESTADUAL DE CAMPINAS - UNICAMP. Tabela brasileira de composição de alimentos: TACO. 4. ed. Campinas: UNICAMP; NEPA, 2011.

VIEIRA, R. F.; LOPES, J. D. S. Produção de brotos comestíveis: feijão moyashi, alfafa, trevo, rabanete e brócolis. Viçosa: CPT, 2001. 108 p.

VILAS BOAS, E. V. B.; BARCELOS, M. F. P.; LIMA, M. A. C. Tempo de germinação e característica físicas, químicas e sensoriais dos brotos de soja e de milho combinado nas formas isoladas e combinadas. Ciência e Agrotecnologia, Lavras, v. 26, n. 1, p. 148-156, 2002.

YOKOMIZO, G. K.; DUARTE, J. B.; VELLO, N. A. Correlações fenotípicas entre tamanho de grãos e outros caracteres em topocruzamentos de soja tipo alimento com tipo grão. Pesquisa Agropecuária Brasileira, Brasília, v. 35, n. 11, p. 2235-2241, 2000. http://dx.doi.org/10.1590/S0100-204X2000001100016. 